\title{
Stool color card use for early detection of biliary atresia
}

\author{
Alicia Reyes-Cerecedo ${ }^{*}$, Judith Flores-Calderón ${ }^{1}$, Miguel Á. Villasís-Keever ${ }^{2}$, José A. Chávez-Barrera ${ }^{3}$, \\ and Elba E. Delgado-González ${ }^{4}$
}

${ }^{1}$ Servicio de Gastroenterología; ${ }^{2}$ Servicio de Unidad en Investigación en Epidemiología Clínica, Unidad Médica de Alta Especialidad Hospital de Pediatría, Centro Médico Nacional Siglo XXI, Dr. Silvestre Frenk Freund; ${ }^{3}$ Servicio de Gastroenterología, Hospital General Gaudencio García, Centro Médico Nacional La Raza; ${ }^{4}$ Área de control de niño sano y tamiz neonatal, Instituto Mexicano del Seguro Social. Mexico City, Mexico

\begin{abstract}
Background: Biliary atresia (BA) is a condition that obstructs biliary flow. If it is not corrected surgically, it can cause cirrhosis and death before 2 years of age. In Mexico, since 2013, the stool color card (SCC) was incorporated into the National Health Card (NHC) for the screening of BA. This study aimed to evaluate the impact of SCC for the detection of BA before and after its incorporation to the NHC. Methods: This is an ambispective, analytical observational study. We included patients with BA treated in two pediatric specialized hospitals. We compared the age of reference, diagnosis, and surgery before and after incorporation of the SCC. Furthermore, a questionnaire was made for the parents to know their perception about the SCC. Results: In 59 children, there was no difference among the time of diagnosis (75 vs. 70 days of life) or at the time of the surgery (84 vs. 90 days of life) between the pre- and post-implementation of the SCC on the NHC. The questionnaire showed that $10(30 \%)$ of the parents received information about the use of the SCC and only $13(38 \%)$ identified the abnormal stool. Conclusions: This study did not show changes in time for the timely detection of BA using SCC. Therefore, it is necessary to reinforce the program in the three levels of care in our country.
\end{abstract}

Key words: Biliary atresia. Abnormal stools. Timely detection.

\section{Uso de la tarjeta colorimétrica visual para la detección oportuna de atresia de vías biliares}

\section{Resumen}

Introducción: La atresia de vías biliares (AVB) es una condición que provoca obstrucción al flujo biliar, y de no corregirse quirúrgicamente, provoca cirrosis y la muerte antes de los 2 años de edad. En México, a partir del año 2013 se incorporó la tarjeta colorimétrica visual (TCV) para la detección oportuna de la AVB a la Cartilla Nacional de Salud (CNS). El objetivo de este estudio fue evaluar el impacto de la TCV para la detección de AVB antes y después de su incorporación a la CNS. Métodos: Estudio ambispectivo, observacional y analítico. Se incluyeron pacientes con AVB atendidos en dos hospitales pediátricos de tercer nivel de atención. Se compararon la edad de referencia, el diagnóstico y la cirugía antes y después de la incorporación de la TCV. Además, se realizó un cuestionario a los padres para conocer su percepción sobre la TCV.

\section{Correspondence:}

*Alicia Reyes-Cerecedo

E-mail: arcaly@ hotmail.com
Date of reception: $23-10-2017$

Date of acceptance: 28-02-2018

DOI: 10.24875/BMHIME.M18000035
Available online: $14-11-2018$ Bol Med Hosp Infant Mex. 2018;75:138-143

www.bmhim.com 
Resultados: En 59 niños no hubo diferencias en la edad al diagnóstico (75 vs 70 días) ni en la edad al momento de la cirugía (84 vs 90 días) entre antes y después de la implementación de la TCV. Solo el 30\% de los padres recibieron información del uso de la TCV y solo el 38\% identificaron las evacuaciones anormales. Conclusiones: Este estudio no mostró cambios en el tiempo para la detección oportuna de AVB mediante el uso de la TCV. Por lo tanto, es necesario reforzar el programa en los tres niveles de atención en nuestro país.

Palabras clave: Atresia de vías biliares. Evacuaciones anormales. Detección oportuna.

\section{Introduction}

Jaundice is a common symptom in newborns, either physiologically or due to the incompatibility of the $\mathrm{ABO} / \mathrm{Rh}$ group. However, if choluria or hypocholia accompany jaundice, the most frequent causes of cholestasis should be suspected, such as biliary atresia (BA) and idiopathic neonatal hepatitis ${ }^{1,2}$.

It is estimated that the worldwide prevalence of $\mathrm{BA}$ ranges from one in every 6000 to 19,000 live births: specifically in Taiwan of 1:6000, in the U.S. of 1:12,000, in Europe of 1:18,000, and in Canada of 1:9000. This condition occurs worldwide but is more frequent among females and in Asian countries ${ }^{3}$. In the first weeks of life, children with BA, in addition to jaundice, show regular appearance without affecting their growth and development, which leads parents and relatives to underestimate this condition. The diagnosis and treatment of BA should not be delayed since its prognosis depends on timely and effective treatment ${ }^{4}$. Roux-en-Y hepatic portoenterostomy or Kasai procedure is the technique of choice as a palliative treatment ${ }^{5,6}$. The age at which this surgery is performed is the most important prognostic factor for survival; for example, it is estimated that $60 \%$ of cases intervened within the first 90 days of extrauterine life will restore bile flow.

In contrast, cases not detected at a shorter time, or in which there is no adequate restoration of bile flow (total bilirubin $>2 \mathrm{mg} / \mathrm{dL}$ ) despite Kasai surgery will develop biliary cirrhosis and short-term complications. Unfortunately, most patients in this situation will die before the second year of life, unless a liver transplant is performed ${ }^{7-13}$.

In several countries with a high incidence of BA, such as Taiwan and Japan ${ }^{14-19}$, a stool color card (SCC) for the screening of patients with suspicion of BA was created since the 90s to decrease the detection age of children with BA. The original card was described by Matsui and Dodoriki ${ }^{20}$ and initially included eight colors marked from 1 to 4 as an abnormal acholic stool. Subsequently, in Taiwan, Chen et al. ${ }^{21}$ modified it with the inclusion of six photographs of the stool of different colors, labeled as acholic, hypocholic, and pale yellow for patients with suspected cholestasis; and normal when stools were yellow, brown, or green. The parents were trained to observe the stool of the children during the first month of life, choosing the corresponding number on the card according to the color of the stool. The acholic stool marked on the color card with numbers 1 , 2 , and 3 was established as abnormal and strongly suspected BA, from which it was determined that all these children should go to the emergency department to make the appropriate diagnosis. With this measure, the age at diagnosis and surgery was reduced from 47 days to 43 days $(p=0.028)^{21-27}$. In Mexico, as of January 2013, the SCC (Fig. 1) was added to the National Health Card (NHC) to carry screening of children with BA. In this context, it is considered that timely detection should provide the opportunity to perform surgery at a younger age, with which the probability of restoring bile flow will be more significant, preventing the progression to liver damage.

The objective of the present study was to determine the impact of the SCC implementation by comparing the reference time of patients seen in two specialized hospitals, as well as the age at when Kasai surgery was performed in children with BA. Furthermore, to assess the knowledge of parents of children with $B A$ on the interpretation of the SCC, a questionnaire was applied during the children hospitalization.

\section{Methods}

A comparative study was carried out in two periods. Children diagnosed with BA who had been sent for diagnostic confirmation to two reference hospitals of the Mexican Social Security Institute (IMSS) (IMSS, for its Spanish acronym) were included the Hospital de Pediatría del Centro Médico Nacional (CMN) Siglo XXI and the Hospital General Gaudencio García, at CMN La Raza. The period of recruitment of patients was between January 2010 and June 2015. Patients were included when they met the following criteria: confirmed diagnosis of BA that is children with jaundice and acholia in whom absence or decrease in the size of the 


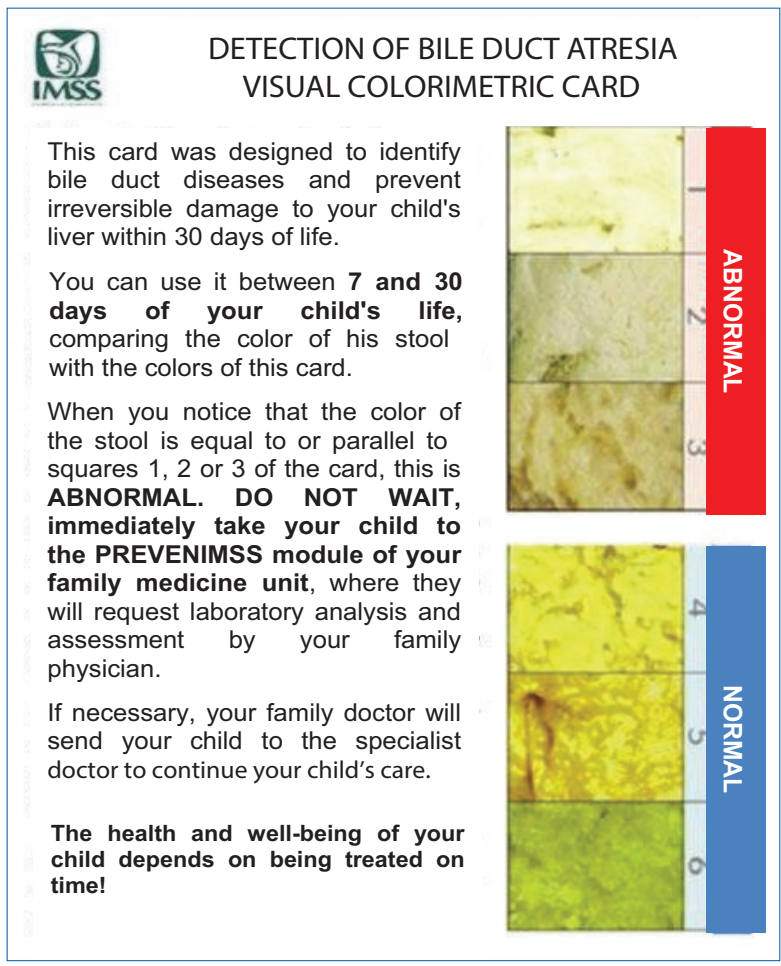

Figure 1. Stool color card.

gallbladder was demonstrated, a histopathological result compatible with BA, and a transoperative cholangiography with the lack of bile flow to the duodenum ${ }^{28,29}$.

To measure the impact of the implementation of the SCC, children were divided into two groups: the first consisted of patients referred from January 2010 to December 2012 (first period), to whom the SCC was not granted; the second group was those referred from January 2013 to June 2015 (second period), to whom the SCC was granted.

Only the mothers of the hospitalized patients during the second period were questioned to determine the knowledge of the SCC. The application of the questionnaire was during the hospitalization, within the first 24$48 \mathrm{~h}$ of admission. The survey had the following direct questions:

1. Who (staff) gave you the SCC?

2. What information did you receive about the use of the SCC?

3. Did you receive the information within the first 5 days of your child's life?

4. Could you identify the abnormal stools, according to the SCC?
5. Do you know what to do if your child has an abnormal stool?

In both groups, the following information was obtained from the clinical records: sex, elements for the confirmation of the BA diagnosis (transoperative cholangiography, histopathological study, jaundice, acholia, and absence or decrease in the size of the gallbladder), age in days in the time of reference to the third level of care, age at the time of diagnosis, and, where appropriate, age at the time of Kasai surgery.

\section{Statistical analysis}

The variables with a qualitative measurement scale are expressed as absolute and relative frequencies; in the case of quantitative variables, they did not present a normal distribution, so they are presented as medians and minimum and maximum values. The comparison between groups was performed with the Mann-Whitney U-test and the $\chi^{2}$ or Fisher's exact tests. Values of $p<0.05$ were considered statistically significant. The statistical package SPSS V.20 was used for the analysis.

\section{Results}

During the study period, 61 children with a diagnosis of BA were identified, with an incidence of 6-20 cases per year (Fig. 2). Two patients were excluded because they underwent Kasai surgery at the second level hospital. Thus, in this study, the results of 59 patients are described. In the first period, before the incorporation of the SCC, there were 27 cases $(70 \%$ male), and in the second period, after the implementation of the SCC, there were 32 cases ( $56 \%$ male). Regarding Kasai surgery, it was performed in 29 of the 59 cases $(49 \%)$, without showing differences between both periods $(p=0.8)$; the rest of the cases were not operated because they were referred after the third month of life (Table 1).

Table 2 compares the characteristics of the reference process, diagnosis, and surgical treatment in the second period, considering whether the patients had undergone Kasai surgery. The median age of referral to the third level hospital was 76.5 versus 86 days $(p=0.3)$, the age at diagnosis was 71.70 days $(p=0.7)$, and the age of surgery was 82 versus 90 days $(p=0.4)$, respectively, without showing a significant difference between periods. In patients who did not have the Kasai surgery, the reference age and diagnosis were higher in the second period (Table 1). 
Table 1. Comparison of the general characteristics of patients with BA

\begin{tabular}{|c|c|c|c|c|c|c|c|}
\hline & \multicolumn{3}{|c|}{ January 2010-December 2012 (Period 1) $(n=27(\%)$} & \multicolumn{4}{|c|}{ January 2013-June 2015 (Period 2) ( $n=32(\%)$} \\
\hline $\begin{array}{l}\text { Sex } \\
\text { Male } \\
\text { Female }\end{array}$ & \multicolumn{3}{|c|}{$\begin{array}{l}19(70) \\
8(30)\end{array}$} & \multicolumn{4}{|c|}{$\begin{array}{l}18(56) \\
14(44)\end{array}$} \\
\hline Portoenterostomy (Kasai) & \multicolumn{3}{|c|}{$14(52)$} & \multicolumn{4}{|c|}{$15(47)$} \\
\hline Total $(n=59)$ & Median & Minimum & Maximum & Median & Minimun & Maximum & $\boldsymbol{p}$ \\
\hline Age of reference (days) & 90 & 30 & 210 & 86 & 28 & 117 & 0.3 \\
\hline Age of diagnosis (days) & 75 & 30 & 150 & 70 & 11 & 110 & 0.7 \\
\hline Age of Kasai surgery (days) & 84 & 22 & 124 & 90 & 28 & 119 & 0.1 \\
\hline
\end{tabular}

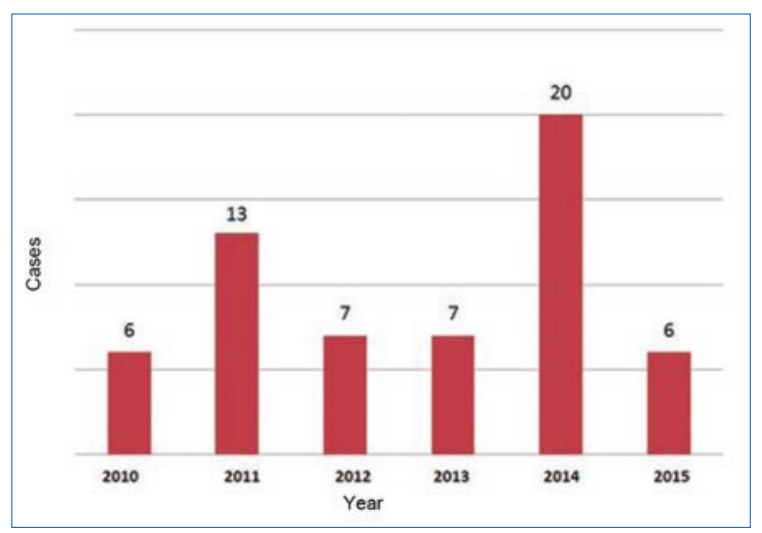

Figure 2. New cases of biliary atresia.

\section{Questionnaire to parents}

The mothers of the children with BA (32) of the second period were interviewed: $97 \%$ (31) answered that they received the NHC in their family medicine unit within the first 5 days of life. However, only in 12 cases $(37 \%)$, the SCC was included in the study. Of these 12 with SCC, 11 parents $(91.6 \%)$ said they knew how to detect and what to do if they identified abnormal stools.

It should be noted that when a subanalysis of these 32 patients was made, no difference was detected between those who had or not the SCC concerning the reference age, the age of diagnosis, and age at of the surgery (Table 2).

\section{Discussion}

In our study, we observed that the inclusion of the SCC to the NHC had no impact on the reference age, the age of diagnosis, or the age of the surgery in patients with BA. Unlike our results, with the incorporation of SCC in other countries, an increase in detection before 60 days of life has been demonstrated, from $72.5 \%$ to $97 \%$ of cases $(p=0.004)^{19-22}$. The same happened in another more recent study, in which after the implementation of the SCC in a cohort of 349 patients, Kasai surgery was performed in the majority at 59 days, and only in $20 \%$, this surgery was carried out after day 908-13.

There is little information regarding the long-term results after the start of these programs for the screening of BA. What is known has been obtained from countries with a high frequency, such as Taiwan, wherein the effectiveness of the SCC in 277 children at 5 and 10 years after starting the program was evaluated retrospectively in 2011, finding a decrease in the age of surgery in $93 \%$ of their operated cases before the 60 days of life. These results show that the process of assimilation of the new strategy for the earlier detection of BA is progressive. It should be noted that initially, before the dissemination of the SCC, a pilot study was conducted. Promotion and training were given to parents and health personnel to identify the color of the stool.

It should be considered that the age at which surgery is performed is the most important prognostic factor for the survival of children with BA, since about $60 \%$ of those operated within the first 90 days of life restore biliary flow ${ }^{22-24}$, even when liver transplantation has been recognized as the treatment of choice in patients with terminal liver disease. In countries as Mexico, where the possibility of transplantation is low due to the lack of donors, limited medical resources, and the high morbidity and mortality in this age group, most of these cases die while waiting for a liver. Therefore, the timely detection of patients with BA and early Kasai surgery is the most effective strategy to reduce mortality ${ }^{20,21}$. However, our study showed that the incorporation of the SCC into the NHC did not impact on the timely 
Table 2. Comparison of the reference age, the age of diagnosis, and age of surgery in children with BA during the second period according to the inclusion or not of the SCC in the NHC (period 2013-2015)

\begin{tabular}{|c|c|c|c|c|c|c|c|}
\hline \multirow[t]{3}{*}{ Variables } & \multicolumn{3}{|c|}{ NHC with SCC } & \multicolumn{3}{|c|}{ NHC without SCC } & \multirow[t]{3}{*}{$p$} \\
\hline & \multicolumn{3}{|c|}{$n=12$} & \multicolumn{3}{|c|}{$n=20$} & \\
\hline & $\begin{array}{c}\text { Median } \\
\text { (days) }\end{array}$ & $\begin{array}{l}\text { Minimum } \\
\text { (days) }\end{array}$ & $\begin{array}{l}\text { Maximum } \\
\text { (days) }\end{array}$ & $\begin{array}{r}\text { Median } \\
\text { (days) }\end{array}$ & $\begin{array}{l}\text { Minimum } \\
\text { (days) }\end{array}$ & $\begin{array}{l}\text { Maximum } \\
\text { (days) }\end{array}$ & \\
\hline $\begin{array}{l}\text { Reference age without Kasai } \\
\text { surgery }\end{array}$ & 172.5 & 81 & 194 & 159 & 121 & 306 & 0.8 \\
\hline $\begin{array}{l}\text { Reference age with Kasai } \\
\text { surgery }\end{array}$ & 76.5 & 29 & 105 & 86 & 56 & 117 & 0.3 \\
\hline $\begin{array}{l}\text { Age of diagnosis without Kasai } \\
\text { surgery }\end{array}$ & 128 & 58 & 194 & 156 & 56 & 282 & 0.3 \\
\hline $\begin{array}{l}\text { Age of diagnosis with Kasai } \\
\text { surgery }\end{array}$ & 71.5 & 56 & 93 & 70 & 56 & 93 & 0.7 \\
\hline $\begin{array}{l}\text { Reference age from the first to } \\
\text { the second level of attention }\end{array}$ & 22.5 & 4 & 48 & 15 & 2 & 50 & 0.9 \\
\hline $\begin{array}{l}\text { Reference age from the second } \\
\text { to the third level of care }\end{array}$ & 14.5 & 3 & 26 & 29 & 1 & 56 & 0.1 \\
\hline $\begin{array}{l}\text { Reference age at the third level } \\
\text { of attention }\end{array}$ & 76.5 & 28 & 105 & 86 & 56 & 117 & 0.3 \\
\hline Age at Kasai surgery & 82 & 28 & 116 & 90 & 63 & 119 & 0.4 \\
\hline
\end{tabular}

NHC: National Health Card; SCC: stool color card

diagnosis and early treatment of children with BA after 2 years of its onset. The success of this program in other countries has been based on sufficient personnel who provide training to parents on the use and identification of feces in the SCC, 24-h telephone communication in case of suspicious BA, and extensive coverage of the SCC. It is clear that the SCC in other countries has been used and almost 20 years after its incorporation the desired impact has been achieved, reducing the number of days until diagnosis and surgery in children with $B A$.

In Mexico, this program has just begun. In 2012, the clinical practice guidelines for the detection and reference of patients with $\mathrm{BA}$ were published ${ }^{22}$, and in 2013, the SCC was incorporated into the NHC. Recently, the platform was implemented nationwide for the notification of suspicious cases of BA. At the present day, in the IMSS and the Ministry of Health, the creation of a critical route for the diagnosis and treatment of $\mathrm{BA}$ is underway. In this guide, all patients with suspicion of BA will be considered as "urgent" for their timely detection and referral (before 45 days of life) to the second and third level care units. With the above, the goal is to treat the complications inherent to this pathology on time, hoping that progressively more patients will be detected at a younger age. In the medium term, a new evaluation will have to be carried after maximizing national dissemination with training programs and updating the responsible personnel in the different levels of care. The strengthening of communication between pediatric services, epidemiology, and family medicine units for the recording, monitoring, and follow-up of cases should have better results.

Within the limitations of the study, we have that the period in which it was carried out is too short to measure the impact of BA detection. Considering that the study was conducted in two reference hospitals of high specialty, the number of patients seems to be very limited, so there could be patients with BA who underwent surgery at another level of care and was not referred.

In our study, there was no change in the timing of the diagnosis and treatment of children with BA after the implementation of the SCC. Therefore, it is necessary to reinforce the program through coverage and delivery of the NHC with SCC, as well as promotion through posters, brochures, and even television campaigns to reach the majority of the population. 


\section{Ethical disclosures}

Protection of human and animal subjects. The authors declare that no experiments were performed

on humans or animals for this study.

Confidentiality of data. The authors declare that they have followed the protocols of their work center on the publication of patient data.

Right to privacy and informed consent. The authors declare that all patients gave their consent for this study.

\section{Conflicts of interest}

The authors declare no conflicts of interest.

\section{Funding}

None.

\section{Acknowledgments}

We thank the staff of clinical archives for their collaboration.

\section{References}

1. Bhatia V, Bavdekar A, Matthai J, Waikar Y, Sibal A. Management of neonatal cholestasis: consensus statement of the pediatric gastroenterology chapter of Indian academy of pediatrics. Indian Pediatr. 2014; 51:203-10.

2. Jiménez-Rivera C, Jolin-Dahel KS, Fortinsky KJ, Gozdyra P, Benchimol El. International incidence and outcomes of biliary atresia. J Pediatr Gastroenterol Nutr. 2013;56:344-54.

3. Fawaz R, Baumann U, Ekong U, Fischler B, Hadzic N, Mack CL, et al. Guideline for the evaluation of cholestatic jaundice in infants: joint recommendations of the North American Society for Pediatric Gastroenterology, Hepatology, and Nutrition and the European Society for Pediatric Gastroenterology, Hepatology, and Nutrition. J Pediatr Gastroenterol Nutr. 2017; 64:154-68.

4. Ramonet M, Ciocca M, Álvarez F. Biliary atresia: a severe illness. Arch Argent Pediatr. 2014;112:542-7.

5. Kasai M, Suzuki S. A new operation for "non-correctable" biliary atresia, hepatic portoenterostomy. Shujyutsu. 1959;13:733-9.
6. Obayashi J, Kawaguchi K, Manabe S, Nagae H, Wakisaka M, Koike J, et al. Prognostic factors indicating survival with native liver after Kasai procedure for biliary atresia. Pediatr Surg Int. 2017;33:1047-52.

7. Ohi R. Biliary atresia. A surgical perspective. Clin Liver Dis. 2000; 4:779-804.

8. Wong KK, Chung PH, Chan IH, Lan LC, Tam PK. Performing Kasai portoenterostomy beyond 60 days of life is not necessarily associated with a worse outcome. J Pediatr Gastroenterol Nutr. 2010;51:631-4.

9. Balistieri W, Bezerra JA, Ryckman F. Biliary atresia and other disorders of the extrahepatic bile ducts. In: Suchy F, Sokol R, Balistieri W, editors. Liver disease in children. Cambridge: Cambridge University Press; 2007. p. 247-69.

10. Flores-Calderón J. Hepatología pediátrica. Rev Gastroenterol Mex. 2013;78:117-9.

11. Hartley JL, Davenport M, Kelly DA. Biliary atresia. Lancet. 2009; 374:1704-13.

12. Bartlett M, Gourley GR. Neonatal jaundice and disorders of bilirubin metabolism. In: Suchy F, Sokol R, Balistieri W, editors. Liver disease in children. Philadelphia: Lippincott, Williams \& Wilkins; 2001. p. 187-94.

13. De Bruyne R, Van Biervliet S, Van de Velde S, Van Winckel M. Clinical practice: neonatal cholestasis. Eur J Pediatr. 2011;170:279-84.

14. Carvalho ED, Santos JL, Silveira TR, Kieling CO, Silva LR, Porta G, et al. Biliary atresia: the Brazilian experience. J Pediatr (Rio J). 2010;86:473-9.

15. Mieli-Vergani G, Howard ER, Portman B, Mowat AP. Late referral for biliary atresia missed opportunities for effective surgery. Lancet. 1989;1:421-3.

16. Neimark E, Leleiko NS. Early detection of biliary atresia raises questions about etiology and screening. Pediatrics. 2011;128:1598-9.

17. Schreiber RA, Butler A. Screening for biliary atresia: it's in the cards. Can Fam Physician. 2017;63:424-5.

18. Schreiber RA, Barker CC, Roberts EA, Martin SR, Álvarez F, Smith L, et al. Biliary atresia: the Canadian experience. J Pediatr. 2007;151:659-65.

19. Queiroz TC, Ferreira AR, Fagundes ED, Roquete ML, Penna FJ. Biliary atresia: evaluation on two distinct periods at a reference pediatric service. Arq Gastroenterol. 2014;51:53-8.

20. Matsui A, Dodoriki M. Screening for biliary atresia. Lancet. 1995:345:1118.

21. Chen SM, Chang MH, Du JC, Lin CC, Chen AC, Lee HC, et al. Screening for biliary atresia by infant stool color card in Taiwan. Pediatrics. 2006;117:1147-53.

22. Jacquemin E. [Screening for biliary atresia and stool colour: method of colorimetric scale]. Arch Pediatr. 2007;14:303-5.

23. Tseng JJ, Lai MS, Lin MC, Fu YC. Stool color card screening for biliary atresia. Pediatrics. 2011;128:1209-15.

24. Lien TH, Chang MH, Wu JF, Chen HL, Lee HC, Chen AC, et al. Effects of the infant stool color card screening program on 5-year outcome of biliary atresia in Taiwan. Hepatology. 2011;53:202-8.

25. Chiu CY, Chen PH, Chan CF, Chang MH, Wu TC. Taiwan Infant Stoo Color Card Study Group. Biliary atresia in preterm infants in Taiwan: a nationwide survey. J Pediatr. 2013;163:100-3.

26. Hsiao $\mathrm{CH}$, Chang MH, Chen $\mathrm{HL}$, Lee HC, Wu TC, Lin CC, et al. Universal screening for biliary atresia using an infant stool color card in Taiwan. Hepatology. 2008;47:1233-40.

27. Diagnóstico temprano y referencia oportuna de la atresia de vías biliares en lactantes menores de dos meses de edad. México: Secretaria de Salud; 2012. Available at: http://www.cenetec-difusion.com/CMGPC/SEDENA-546-13/ER.pdf.

28. Hwang SM, Jeon TY, Yoo SY, Choe YH, Lee SK, Kim JH. Early US findings of biliary atresia in infants younger than 30 days. Eur Radiol. 2018;28:1771-7.

29. Zhou LY, Chen SL, Chen HD, Huang Y, Qiu YX, Zhong W, et al. Percutaneous US-guided cholecystocholangiography with microbubbles for assessment of infants with US findings equivocal for biliary atresia and gallbladder longer than $1.5 \mathrm{~cm}$ : a pilot study. Radiology. 2018;286:1033-9. 